\title{
The interaction between suicidal ideation, insomnia symptoms, and student status
}

\author{
Jodie C. Stevenson ${ }^{1}$, Kamila Irvine ${ }^{1}$, Sarah Allen ${ }^{2}$ and Umair Akram ${ }^{3, \star ~(D) ~}$ \\ ${ }^{1}$ School of Psychology, University of Lincoln, Lincoln, UK, ${ }^{2}$ School of Social Sciences, Humanities and Law University of \\ Teesside, Middlesbrough, UK, and ${ }^{3}$ Department of Psychology, Sociology and Politics, Sheffield Hallam University, \\ Sheffield, UK \\ ${ }^{\star}$ Corresponding author. Email: u.akram@shu.ac.uk
}

(Received 02 September 2021; Revised 29 October 2021; Accepted 29 October 2021)

\begin{abstract}
Evidence demonstrates increased vulnerability to thoughts and behaviors related to suicide (i.e., suicidal ideation) in students. This study examined the interaction between insomnia-symptoms and student-status (students vs. non-students) on reports of suicidal thoughts of behaviors. A total of $363(N=363)$ university students and $300(N=300)$ members of the general population provided complete data on measures of insomnia-symptoms and suicidal ideation. Students indicated greater reports of both total and lifetime ideation while also considering suicidal behavior within the past year. However, no differences were observed in reports of possible future attempt(s) and the disclosure of suicidal thoughts and behaviors to another person. Moreover, students presenting concurrent symptoms of insomnia reported significantly elevated levels of suicidal ideation relative to nonstudents. These outcomes highlight the possible role of insomnia symptoms in accentuating suicidal thoughts and behaviors in the student population.
\end{abstract}

Key words: mental health; students; suicide

\section{Introduction}

Suicide is the second leading cause of death among young adults (WHO, 2014), and increased vulnerability to thoughts and behaviors related to suicide (i.e., suicidal ideation) is evidenced in the student population (O'Neill et al., 2018). In the UK, data indicate a twofold increase in suicide deaths among higher education (HE) students over the past decade, with 95 completed attempts in the 2016/17 academic year (Caul, 2018). Estimates of lifetime suicidal ideation among UK HE students range from 31 to 72.4\% (Akram et al., 2020; Dhingra et al., 2019; O'Neill et al., 2018), and between 9.8 and 14.6\% in the general population (Casey et al., 2008).

The experience of suicidal ideation serves as a risk factor for future suicidal behavior and completion (Ribeiro et al., 2017), often presenting with extreme psychological distress (Garlow et al., 2008). Although suicidal ideation may occur in the absence of other psychiatric disorders (Chiles \& Strosahi, 2005), studies have typically shown that suicidal ideation co-occurs alongside underlying, yet treatable, mental health difficulties (Cracknell, 2015). Insomnia is a recognized public health concern, often related with and leading to long-term physical and mental exhaustion, disturbed mood, concentration and memory deficits, social isolation, body image disturbance, and suicidal ideation (Akram et al., 2019; 2020; 2021a; 2021b; Baglioni et al., 2011; Byrne, 2019; Choueiry et al., 2016; Ellis et al., 2014; Kyle et al., 2010;

\footnotetext{
(c) The Author(s), 2021. Published by Cambridge University Press. This is an Open Access article, distributed under the terms of the Creative Commons Attribution licence (http://creativecommons.org/licenses/by/4.0), which permits unrestricted re-use, distribution and reproduction, provided the original article is properly cited.
} 
Perlis et al., 1997; Ypsilanti et al., 2018). Indeed, a recent review of sleep and suicidal ideation data in students (Russell et al., 2019) and the general population (Harris et al., 2020; Liu et al., 2020) found insomnia to be consistently associated with an increased risk of future suicidal thoughts and behaviors (Bernert et al., 2017; Hom et al., 2019; Littlewood et al., 2019; Shi et al., 2021).

\section{Objectives}

Although a number of studies have examined the relationship between insomnia and suicidal ideation in specific populations (e.g., military and prison: Carli et al., 2011; Hom et al., 2017), few compare differences between students and nonstudents. Furthermore, studies sampling students from UK institutions remain sparse or limiting samples to particular institutions or course topic (Cardwell et al., 2013). The overall aim of this study was to examine the interaction between insomnia-symptoms (normal-sleepers vs. insomnia-symptoms) and student-status (students vs. non-students) on reports of suicidal thoughts of behaviors. Student psychological well-being is an important global issue of growing interest. Contemporary students face stressors beyond the "traditional" stressors associated with pursuing HE (e.g., exam pressure and deadlines: El Ansari et al., 2011). Research has shown that the transition into university is associated with documented psychological disturbances (Macaskill, 2013). In line with independent prevalence estimates (Casey et al., 2008), we expect greater reports of suicidal thoughts and behaviors among students. In addition, when compared with nonstudents, we expect levels of suicidal ideation to be accentuated among students presenting insomnia symptoms.

\section{Methods}

\subsection{Sample and procedure}

The protocol was approved by the Sheffield Hallam University Research Ethics Committee. A crosssectional online questionnaire-based study was implemented comprising of questions designed to examine symptoms of insomnia and suicidal ideation. Students from three UK universities were recruited through institutional course participation schemes, social media, and faculty emails. Members of the general population were recruited using social media platforms and online forums. Overall, 780 participants began or accessed the questionnaire, after incomplete entries were discarded $636 \mathrm{com}$ pleted entries (mean age $=28.95 \pm 13.03$, range $18-100,88 \%$ female; final response rate $=81.5 \%$ ) were kept for analysis. This sample size was sufficient for a $95 \%$ confidence level, exceeding our target of 500 responses leaving an acceptable 4.5\% margin of error (Niles, 2006). SPSS (version 24, IBM Corp., Armonk, NY) was used to perform formal statistical analyses with significance considered at the $p<.05$ level.

\subsection{Measures}

Suicidal ideation was examined using the Suicidal Behaviors Questionnaire-Revised (SBQ-R; Osman et al., 2001). Specifically, four items examine lifetime ideation/attempt, frequency of ideation over the past 12 months, telling someone else about ideation, and likelihood of attempting suicide in the future. Items can be analyzed individually and summated to create a total score ranging between 3 and 18 . Higher total scores indicate greater risk of suicidal ideation. A score of $\geq 7$ indicates significant risk for suicidal behavior (sensitivity $93 \%$ and specificity $91 \%$ in the adult general population; Osman et al., 2001). Internal consistency was high in the present sample $(\alpha=0.86)$.

Insomnia symptoms were assessed using Sleep Condition Indicator (SCI), a clinical screening tool developed to appraise insomnia symptoms against the DSM-5 criteria for Insomnia Disorder (Espie et al., 2014). The scale consists of eight items each scored between 0 and 4 designed to examine insomnia symptomology during the last month. Specifically, questions pertain to sleep onset latency, awakenings during the night, perceived sleep quality, impairment to daytime functioning, and symptom persistence. 
Items are summed to create a total score between 0 and 32, with lower scores indicating greater insomnia symptom severity. Internal consistency was high in the present sample $(\alpha=0.87)$.

\section{Results}

Participants were stratified by student and sleep status. Specifically, normal-sleepers $(n=300$; $26.52 \pm 11.42$ years, $86 \%$ female) were determined as those scoring $>17$ on the SCI, whereas those experiencing insomnia-symptoms $(n=336 ; 31.11 \pm 13.97$ years, $90 \%$ female $)$ were determined as scoring $\leq 16$. A score of 16 or less on the SCI indicates probable insomnia disorder. Although no sex differences were observed in relation to sleep status $\left(X^{2}(2)=4.91, p=.086\right)$, the insomnia group was comprised significantly older $(31.11 \pm 13.97)$ adults relative to normal-sleepers $(26.53 \pm 11.42) . N=393$ participants confirmed student status $(21.30 \pm 5.86$ years, $87 \%$ female $)$ and $N=244$ identified as nonstudent $(41.23 \pm 11.93$ years, $90 \%$ female). As expected, students were significantly younger than nonstudents $(F(1,635)=788.84, p=.001)$. No sex differences were observed in relation to student-status $\left(X^{2}(2)=1.87, p=.393\right)$. Mean scores grouped by student status are presented in Table 1.

A series of one-way analysis of variance (ANOVA) examined differences in insomnia symptoms and suicidal ideation between students and nonstudents. Here, students presented increased reports of insomnia symptoms $(F(1,636)=13.55, p=.001)$ and total suicidal ideation scores $(F(1,636)=5.45$, $p=.02)$ compared to nonstudents. Individual examination of SBQ-R items revealed greater reports of lifetime ideation/attempt $(F(1,636)=4.59, p=.03)$, frequency of ideation over the past 12 months $(F$ $(1,636)=5.32, p=.02)$. However, no group differences were observed in telling someone else about ideation $(F(1,636)=1.98, p=.16)$ and the likelihood of attempting suicide in the future ( $F$ $(21,636)=3.69, p=.06)$ among students.

A 2 (sleep: normal-sleeper vs. insomnia-symptoms) $\times 2$ (student-status: student vs. nonstudent) mixed measures ANOVA with total SBQ-R scores as the dependant variable examined the interaction between sleep status and student status. The results demonstrated significant main effects of sleep ( $F$ $(1,633)=65.72, p=.001)$ and student-status $(F(1,633)=11.74, p=.001)$. Although no sleep $\times$ studentstatus interaction was observed $(F(1,633)=2.10, p=.15)$, individual analysis of total suicidal ideation scores in the insomnia group revealed a significant difference between students $(7.70 \pm 4.03)$ and nonstudents $(6.36 \pm 3.54: F(1,335)=10.09, p=.002$, see Figure 1$)$. However, total suicidal ideation scores in normal-sleepers failed to differ between students $(5.08 \pm 2.74)$ and nonstudents $(4.54 \pm 2.15: F$ $(1,298)=2.85, p=.09)$. Therefore, the experience of insomnia symptoms may contribute to suicidal thoughts and behaviors in the student population.

Table 1. Mean scores for each measure for the whole sample and separated by suicidal ideation risk

\begin{tabular}{|c|c|c|c|c|c|}
\hline & $\begin{array}{c}\text { Whole sample } \\
\qquad M \pm \mathrm{SD}\end{array}$ & $\begin{array}{c}\text { Non-student } \\
M \pm \mathrm{SD}\end{array}$ & $\begin{array}{l}\text { Student } \\
M \pm S D\end{array}$ & $F$ & $p$ \\
\hline Insomnia (SCI) & $16.25 \pm 7.62$ & $14.84 \pm 7.73$ & $17.11 \pm 7.42$ & 13.55 & $.001^{\star \star}$ \\
\hline \multicolumn{6}{|l|}{ Suicidal ideation } \\
\hline SBQ-R total & $6.07 \pm 3.50$ & $5.66 \pm 3.19$ & $6.32 \pm 3.65$ & 5.45 & $.020^{*}$ \\
\hline Lifetime ideation & $1.98 \pm 0.98$ & $1.88 \pm 0.94$ & $2.05 \pm 1.00$ & 4.60 & $.032^{*}$ \\
\hline 12-month frequency & $1.80 \pm 1.16$ & $1.66 \pm 1.04$ & $1.88 \pm 1.22$ & 5.32 & $.021^{*}$ \\
\hline Threat of attempt & $1.34 \pm 0.63$ & $1.30 \pm 0.57$ & $1.37 \pm 0.70$ & 1.98 & .160 \\
\hline Future attempt & $1.00 \pm 1.30$ & $0.82 \pm 1.23$ & $1.02 \pm 1.34$ & 3.69 & .055 \\
\hline
\end{tabular}

Abbreviations: \pm , standard deviation; SBQ-R, Suicide Behaviors Questionnaire Revised; SCI, Sleep Condition Indicator. 


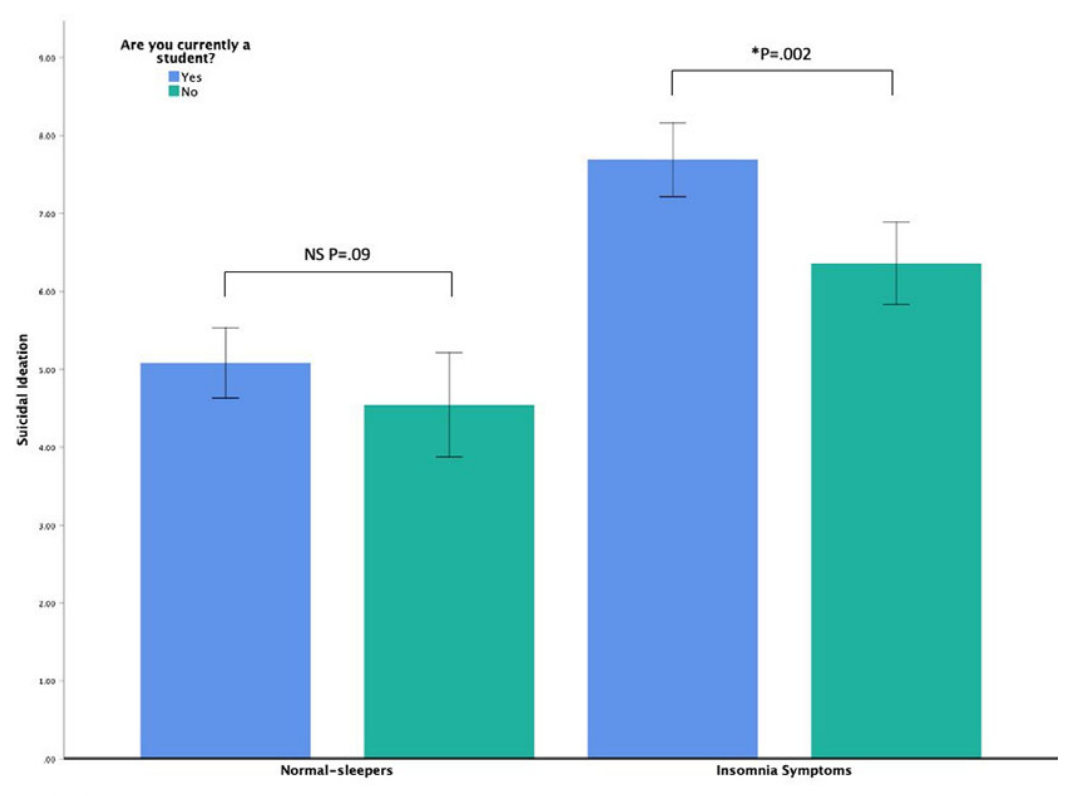

Error bas: 95x C

Figure 1. Bar chart decomposing the interaction between sleep (normal-sleeper vs. insomnia symptoms) and student status (student vs. nonstudent) on total SBQ-R scores. No difference in total SBQ-R scores observed between normal sleeping students and nonstudents (left). Significantly higher total SBQ-R scores displayed among students with insomnia symptoms (right). Abbreviations: SBQ-R, Suicidal Behaviors Questionnaire-Revised. *Significance at $<.01$.

\section{Discussion}

This study examined the interaction between sleep-status (insomnia-symptoms: normal vs. insomnia) and student-status (students vs. nonstudents) on reports of suicidal thoughts of behaviors. Partially supporting our first hypothesis, when compared to nonstudents, students indicated greater reports of both total and lifetime ideation while also considering suicidal behavior within the past year. However, no differences were observed in reports of possible future attempt(s) and the disclosure of suicidal thoughts and behaviors to another person. These outcomes are in line with previous estimates of suicidal ideation which from population-specific studies appear greater in the UK student population (31-72.4\%) relative to the UK general public 9.8-14.6\% (Akram et al., 2021b; Casey et al., 2008; Dhingra et al., 2019; O'Neill et al., 2018). Moreover, we highlight the specific nature of elevated suicidal thoughts and behaviors in the student population.

Overall, students exhibited greater levels of insomnia-symptoms. Interestingly, we observed significantly elevated suicidal ideation among students in the insomnia group when compared with nonstudents. These outcomes highlight the possible role of insomnia symptoms in accentuating suicidal thoughts and behaviors in the student population (Bernert et al., 2017; Hom et al., 2019; Littlewood et al., 2019; Russell et al., 2019; Shi et al., 2021). The current student population was comprised younger adults in a transitional life period. In this context, the stress of academic life may perpetuate symptoms of insomnia due to increased worry and ruminative thinking when attempting to initiate sleep. This thought pattern is known to facilitate negatively toned cognitive activity, arousal and distress that contributes to delayed sleep-onset latency (Harvey, 2002). In turn, daytime consequences of insomnia diminish the capacity to sufficiently cope with social and interpersonal difficulties and academic stressors faced by students, which may precipitate the onset of psychiatric difficulty (Staner, 2010) and suicidal thoughts and behaviors (Becker et al., 2018; Holdaway et al., 2018).

Student-based mental health services in the UK should refine screening processes to identify at-risk populations and engage in early intervention (Beiter et al., 2015). Psychiatric problems can be readily identified and targeted for intervention, and screening for sleep-disorders, such as insomnia would prove 
useful when considering its relationship with suicidal ideation among students (Becker et al., 2018; Holdaway et al., 2018; Sheaves et al., 2016).

The present sample comprised mostly of female participants, and as such the present findings may not be fully generalizable to males. However, it should be noted that women are more likely than men to experience insomnia (Zhang \& Wing, 2006). Moreover, the cross-sectional nature of the present study limits our ability to draw conclusions about causal relationships. Indeed, it is possible that the experience of suicidal ideation leads to or accentuates pre-existing sleep disturbances. Despite these caveats, we highlight the possible role of insomnia symptoms in accentuating suicidal thoughts and behaviors in the student population. Further longitudinal research should explore the role of disturbed sleep in predicting suicidal thoughts and behaviors in the UK student population.

Funding statement. No funding was received for this research.

Author contribution. The experiment was designed and conceived by UA. Data was collected by U.A., K.I., S.A., J.S. Data was analysed by U.A. \& J.S. An initial version of the manuscript was written by U.A. and J.S. Following, input was sought from K.I., S.A. All authors approved the final version of the manuscript.

Conflict of interest. No conflicts of interest declared in relation to this paper.

Data Availability Statement. Data will be made available on reasonable request.

\section{References}

Akram, U., Allen, S., Stevenson, J. C., Lazarus, L., Ypsilanti, A., Ackroyd, M., Chester, J., Longden, J., Peters, C., \& Irvine, K. R. (2021a). Self-disgust as a potential mechanism underlying the association between body image disturbance and suicidal thoughts and behaviours. Journal of Affective Disorders, 297, 634-640. https://doi.org/10.1016/j.jad.2021.10.063

Akram, U., Allen, S. F., Stevenson, J. C., Lazuras, L., Ackroyd, M., Chester, J., Longden, J., Peters, C., \& Irvine, K. R. (2021b). Homogeneity of cognitive and behavioural processes underlying the relationship between insomnia and body image disturbance. Cognitive Processing, 22, 701-709.

Akram, U., Ypsilanti, A., Drabble, J., \& Lazuras, L. (2019). The role of physical and behavioral self-disgust in relation to insomnia and suicidal ideation. Journal of Clinical Sleep Medicine, 15(3), 525-527.

Akram, U., Ypsilanti, A., Gardani, M., Irvine, K., Allen, S., Akram, A., Drabble, J., Bickle, E., Kaye, L., Lipinski, D., Matuszyk, E., Sarlak, H., Steedman, E., \& Lazarus, L. (2020). Prevalence and psychiatric correlates of suicidal ideation in UK university students. Journal of Affective Disorders, 272, 191-197.

Baglioni, C., Battagliese, G., Feige, B., Spiegelhalder, K., Nissen, C., Voderholzer, U., Lombardo, C., \& Riemann, D. (2011). Insomnia as a predictor of depression: A meta-analytic evaluation of longitudinal epidemiological studies. Journal of Affective Disorders, 135(1-3), 10-19.https://doi.org/10.1016/j.jad.2011.01.011

Becker, S. P., Dvorsky, M. R., Holdaway, A. S., \& Luebbe, A. M. (2018). Sleep problems and suicidal behaviors in college students. Journal of Psychiatric Research, 99, 122-128. https://doi.org/10.1016/j.jpsychires.2018.01.009

Beiter, R., Nash, R., McCrady, M., Rhoades, D., Linscomb, M., Clarahan, M., \& Sammut, S. (2015). The prevalence and correlates of depression, anxiety, and stress in a sample of college students. Journal of Affective Disorders, 173, 90-96.

Bernert, R. A., Hom, M. A., Iwata, N. G., \& Joiner, T. E. (2017). Objectively assessed sleep variability as an acute warning sign of suicidal ideation in a longitudinal evaluation of young adults at high suicide risk. The Journal of Clinical Psychiatry, 78(6), e678-e687.

Byrne, E. M. (2019). The relationship between insomnia and complex diseases-insights from genetic data. Genome Medicine, 11(1), 1-3. https://doi.org/10.1186/s13073-019-0668-0

Cardwell, J. M., Lewis, E. G., Smith, K. C., Holt, E. R., Baillie, S., Allister, R., \& Adams, V. J. (2013). A cross-sectional study of mental health in UK veterinary undergraduates. Veterinary Record, 173, 266. https://doi.org/10.1136/vr.101390

Carli, V., Roy, A., Bevilacqua, L., Maggi, S., Cesaro, C., \& Sarchiapone, M. (2011). Insomnia and suicidal behaviour in prisoners. Psychiatry Research, 185(1-2), 141-144. https://doi.org/10.1016/j.psychres.2009.10.001

Casey, P., Dunn, G., Kelly, B. D., Lehtinen, V., Dalgard, O. S., Dowrick, C., \& Ayuso-Mateos, J. L. (2008). The prevalence of suicidal ideation in the general population: Results from the outcome of depression international network (ODIN) study. Social Psychiatry and Psychiatric Epidemiology, 43(4), 299-304. https://doi.org/10.1007/s00127-008-0313-5

CaulS. (2018). Estimates of suicides among higher education students by sex, age and ethnicity. Analysis based on mortality records linked to Higher Education Statistics Agency (HESA) Student records. Office for National Statistics, UK. 
Chiles, J. A., \& Strosahl, K. D. (2005). Clinical manual for assessment and treatment of suicidal patients. American Psychiatric Publishing, Inc.

Choueiry, N., Salamoun, T., Jabbour, H., El Osta, N., Hajj, A., \& Khabbaz, L. R. (2016). Insomnia and relationship with anxiety in university students: A cross-sectional designed study. PLoS One, 11(2), e0149643. 10.1371/journal.pone.0149643

Cracknell, B. (2015). Improving the quality of initial management of self harm and suicide patients in A $+\mathrm{E}$ at the James Paget Hospital. BMJ Quality Improvement Reports, 4(1), u207272-u2w2919.

Dhingra, K., Klonsky, E. D., \& Tapola, V. (2019). An empirical test of the three-step theory of suicide in UK University students. Suicide and Life-Threatening Behavior, 49(2), 478-487. https://doi.org/10.1111/sltb.12437

El Ansari, W., Stock, C., John, J., Deeny, P., Phillips, C., Snelgrove, S., Adetunji, H., Hu, X., Parke, S., Stoate, M., \& Mabhala, A. (2011). Health promoting behaviours and lifestyle characteristics of students at seven universities in the UK. Central European Journal of Public Health, 19, 197-204. https://doi.org/10.21101/cejph.a3684

Ellis, J. G., Perlis, M. L., Bastien, C. H., Gardani, M., \& Espie, C. A. (2014). The natural history of insomnia: Acute insomnia and first-onset depression. Sleep, 37(1), 97-106. https://doi.org/10.5665/sleep.3316

Espie, C. A., Kyle, S. D., Hames, P., Gardani, M., Fleming, L., \& Cape, J. (2014). The sleep condition indicator: A clinical screening tool to evaluate insomnia disorder. BMJ Open, 4(3), e004183. https://doi.org/10.1136/bmjopen-2013-004183

Garlow, S. J., Rosenberg, J., Moore, J. D., Haas, A. P., Koestner, B., Hendin, H., \& Nemeroff, C. B. (2008). Depression, desperation, and suicidal ideation in college students: Results from the American Foundation for Suicide Prevention College Screening Project at Emory University. Depression and Anxiety, 25(6), 482-488. https://doi.org/10.1002/da.20321

Harris, L. M., Huang, X., Linthicum, K. P., Bryen, C. P., \& Ribeiro, J. D. (2020). Sleep disturbances as risk factors for suicidal thoughts and behaviours: a meta-analysis of longitudinal studies. Scientific Reports, 10(1), 1-11.

Harvey, A. G. (2002). A cognitive model of insomnia. Behaviour Research and Therapy, 40(8), 869-893.

Holdaway, A. S., Luebbe, A. M., \& Becker, S. P. (2018). Rumination in relation to suicide risk, ideation, and attempts: Exacerbation by poor sleep quality?. Journal of Affective Disorders, 236, 6-13. https://doi.org/10.1016/j.jad.2018.04.087

Hom, M. A., Chu, C., Schneider, M. E., Lim, I. C., Hirsch, J. K., Gutierrez, P. M., \& Joiner, T. E. (2017). Thwarted belongingness as an explanatory link between insomnia symptoms and suicidal ideation: Findings from three samples of military service members and veterans. Journal of Affective Disorders, 209, 114-123. https://doi.org/10.1016/ j.jad.2016.11.032

Hom, M. A., Stanley, I. H., Chu, C., Sanabria, M. M., Christensen, K., Albury, E. A., Rogers, M. L., \& Joiner, T. E. (2019). A longitudinal study of psychological factors as mediators of the relationship between insomnia symptoms and suicidal ideation among young adults. Journal of Clinical Sleep Medicine, 15(1), 55-63.

Kyle, S. D., Morgan, K., \& Espie, C. A. (2010). Insomnia and health-related quality of life. Sleep Medicine Reviews, 14(1), 69-82. https://doi.org/10.1016/j.smrv.2009.07.004

Littlewood, D. L., Kyle, S. D., Carter, L. A., Peters, S., Pratt, D., \& Gooding, P. (2019). Short sleep duration and poor sleep quality predict next-day suicidal ideation: An ecological momentary assessment study. Psychological Medicine, 49(3), 403-411.

Liu, R. T., Steele, S. J., Hamilton, J. L., Do, Q. B., Furbish, K., Burke, T. A., ... Gerlus, N. (2020). Sleep and suicide: A systematic review and meta-analysis of longitudinal studies. Clinical Psychology Review, 101895.

Macaskill, A. (2013). The mental health of university students in the United Kingdom. British Journal of Guidance \& Counselling, 41(4), 426-441. https://doi.org/10.1080/03069885.2012.743110

NilesR. (2006). Robert Niles' journalism help: Statistics every writer should know. Available from: http://www. robertniles. com/stats.

O’Neill, S., McLafferty, M., Ennis, E., Lapsley, C., Bjourson, T., Armour, C., Murphy, S., Bunting, B., \& Murray, E. (2018). Socio-demographic, mental health and childhood adversity risk factors for self-harm and suicidal behaviour in College students in Northern Ireland. Journal of Affective Disorders, 239, 58-65. https://doi.org/10.1016/j.jad.2018.06.006

Osman, A., Bagge, C. L., Gutierrez, P. M., Konick, L. C., Kopper, B. A., \& Barrios, F. X. (2001). The suicidal behaviors questionnaire-revised (SBQ-R): Validation with clinical and nonclinical samples. Assessment, 8 (4), 443-454. https://doi.org/ $10.1177 / 107319110100800409$

Perlis, M. L., Giles, D. E., Buysse, D. J., Thase, M. E., Tu, X., \& Kupfer, D. J. (1997). Which depressive symptoms are related to which sleep electroencephalographic variables?. Biological Psychiatry, 42(10), 904-913. https://doi.org/10.1016/S0006-3223( 96)00439-8

Ribeiro, J. D., Gutierrez, P. M., Joiner, T. E., Kessler, R. C., Petukhova, M. V., Sampson, N. A., \& Nock, M. K. (2017). Health care contact and suicide risk documentation prior to suicide death: Results from the Army Study to Assess Risk and Resilience in Servicemembers (Army STARRS). Journal of Consulting and Clinical Psychology, 85(4), 403.

Russell, K., Allan, S., Beattie, L., Bohan, J., MacMahon, K., \& Rasmussen, S. (2019). Sleep problem, suicide and self-harm in university students: A systematic review. Sleep Medicine Reviews, 44, 58-69. https://doi.org/10.1016/j.smrv.2018.12.008

Sheaves, B., Porcheret, K., Tsanas, A., Espie, C. A., Foster, R. G., Freeman, D., Harrison, P. J., Wulff, K., \& Goodwin, G. M. (2016). Insomnia, nightmares, and chronotype as markers of risk for severe mental illness: Results from a student population. Sleep, 39(1), 173-181. https://doi.org/10.5665/sleep.5342 
Shi, X., Zhu, Y., Wang, S., Wang, A., Chen, X., Li, Y., \& Jiang, L. (2021). The prospective associations between different types of sleep disturbance and suicidal behavior in a large sample of Chinese college students. Journal of Affective Disorders, 279, 380-387.

Staner, L. (2010). Comorbidity of insomnia and depression. Sleep Medicine Reviews, 14(1), 35-46. https://doi.org/10.1016/ j.smrv.2009.09.003

World Health Organisation. (2014). Suicide in the world: global health esitmates [booklet]. https://www.who.int/mental_ health/prevention/suicide/suicideprevent/en/

Ypsilanti, A., Lazuras, L., Robson, A., \& Akram, U. (2018). Anxiety and depression mediate the relationship between selfdisgust and insomnia disorder. Sleep Health, 4(4), 349-351.

Zhang, B., \& Wing, Y. K. (2006). Sex differences in insomnia: A meta-analysis. Sleep, 29(1), 85-93. https://doi.org/10.1093/ sleep/29.1.85

Cite this article: Stevenson JC, Irvine K, Allen S, Akram U (2021). The interaction between suicidal ideation, insomnia symptoms, and student status Experimental Results, 2, e33, 1-11. https://doi.org/10.1017/exp.2021.25 


\section{Peer Reviews}

\section{Reviewing editor: Dr. Teresa Ober}

University of Notre Dame, Department of Psychology, E418 Corbett Family Hall, Notre Dame, Indiana, United States, 46556

This article has been accepted because it is deemed to be scientifically sound, has the correct controls, has appropriate methodology and is statistically valid, and has been sent for additional statistical evaluation and met required revisions.

doi:10.1017/exp.2021.25.pr1

Review 1: The interaction between suicidal ideation, insomnia symptoms, and student status Reviewer: Dr. Seonaid Cleare

University of Glasgow, Glasgow, United Kingdom of Great Britain and Northern Ireland, G12 8QQ

Date of review: 30 September 2021

Conflict of interest statement. Reviewer declares none

Comments to the Author: This is a nice and concise $\mathrm{m} / \mathrm{s}$ looking at the association between insomnia status and suicidal ideation in students compared to non-students. I like the $\mathrm{m} / \mathrm{s}$ and have some questions/comments the answers to which I think might add clarity to the $\mathrm{m} / \mathrm{s}$.

1. I would be cautious in using phases such as 'completed suicides' suicide deaths would work.

2. Although rates of suicide has increased in student populations, it remains lower than general population.

3. Some of the references used are quite outdated (e.g. Casey et al, 2008) - several more recent sources exist.

4. I'm not convinced that social media platforms/ online forums = general population sample.

5. Should sleep status/ demographics be in measures?

6. Were the data assessed for age/gender differences? How do the data compare to sleep in these groups?

I hope the authors find these suggestions useful in revising their $\mathrm{m} / \mathrm{s}$.

\section{Score Card}

Presentation

Is the article written in clear and proper English? (30\%)

Is the data presented in the most useful manner? (40\%)

Does the paper cite relevant and related articles appropriately? (30\%) 
Does the abstract correctly embody the content of the article? (25\%)

Does the introduction give appropriate context? (25\%)

Is the objective of the experiment clearly defined? (25\%)

Analysis

Does the discussion adequately interpret the results presented? (40\%)

Is the conclusion consistent with the results and discussion? (40\%)

Are the limitations of the experiment as well as the contributions of the experiment clearly outlined? $(20 \%)$ 


\title{
Review 2: The interaction between suicidal ideation, insomnia symptoms, and student status
}

\author{
Reviewer: Mr. Daniel Bradford ${ }^{1}$ \\ ${ }^{1}$ University of Glasgow MRC/CSO Social and Public Health Sciences Unit, Glasgow, United Kingdom of Great Britain and \\ Northern Ireland, G12 8RZ
}

Date of review: 26 October 2021

(c) The Author(s), 2021. Published by Cambridge University Press. This is an Open Access article, distributed under the terms of the Creative Commons Attribution licence (http://creativecommons.org/licenses/by/4.0), which permits unrestricted re-use, distribution and reproduction, provided the original article is properly cited.

Conflict of interest statement. Reviewer declares none.

Comments to the Author: A clear and interesting report that gives important context to insomnia and suicidal ideation in students compared to general adult population. Measures and methods are appropriate. Enjoyed reading. If word count allows the manuscript would be improved by expanding discussion: 1) Mention that sleep disturbances are associated with increased subsequent suicidal ideation using evidence from longitudinal studies (suggested references below). This will help overcome the limitation re. cross-sectional studies. 2) Address the significant age difference between students and general population subgroups. Perhaps reference studies which compare insomnia and/or mental distress between students and similarly-aged peers to add partial justification of older age in present non-student sample.

Section1Para1

Incorrect reference: Baker2016 doesn't mention students.

ONeil2018 doesn't compare students to general population, but I appreciate this contrast is handled later on.

S2P1

"Furthermore, studies sampling..." Slightly unclear sentence.

$\mathrm{S} 3 \mathrm{P} 2+\mathrm{P} 3$

Add possible range of scores for measures to give context to Table 1 values.

S4P1

Mean ages of insomnia (26.52 and 31.11) and student status (21.30 and 41.23) subgroups don't make sense compared to overall mean age (41.02). Check values.

S4 P3

"Therefore, the experience of insomnia symptoms may accentuate suicidal ideation specifically amongst the student population." Opposite might be true: ideation as source of poorer sleep. I don't disagree that insomnia is a cause rather than effect, based on longitudinal studies (e.g., 10.1017/ S0033291718001009, 10.4088/JCP.16m11193).

Akram 2020 now has full publication details available, can update [In Press] placeholder.

Typo: "asey, P..."

Missing from reference list:

Ribeiro2016

Cracknell2015

Niles2006

Harvey 2002 
Is the data presented in the most useful manner? (40\%)

Does the paper cite relevant and related articles appropriately? (30\%)

\section{Context}

4.2

Does the title suitably represent the article? (25\%)

Does the abstract correctly embody the content of the article? (25\%)

Does the introduction give appropriate context? (25\%)

Is the objective of the experiment clearly defined? (25\%)

Analysis

Are the limitations of the experiment as well as the contributions of the experiment clearly outlined? (20\%) 